\title{
Strategies and Paths for Social Organizations to Participate in Public Policies
}

\author{
Lin Pan \\ PhD candidate, School of Public Affairs, University of Science and Technology of China, \\ No. 96 JinZhai Road Baohe District, Hefei, Anhui 230026, China; \\ Lecturer, Anhui Administration Institute \& Anhui Economic Management Institute, \\ Wangjiang Road, Hefei, Anhui, China
}

Rong-Ting Zhou

Professor, School of Humanities and Social Science, University of Science and Technology of China, No. 96 JinZhai Road Baohe District, Hefei, Anhui 230026, China

Received: April 2, 2018 Accepted: May 28, 2018 Published: May 30, 2018

doi: 10.5296/jsss.v5i2.13219 URL: http://doi.org/10.5296/jsss.v5i2.13219

\begin{abstract}
The participation of social organizations in the process of public policy can make up for the limitations of the existing system, effectively safeguard the social interests at the core of the public interests and promote the sustainable development of the diversified society. However, in the process of participating in public policy, the social organizations of our country still face some factors such as unclear legal status of participation, insufficient operating funds, lack of professional talents and imperfect supervision system. We should take strategies and measures from the aspects of law, system and the self construction of non-governmental organizations, expand the scope and level of social organizations to participate in public policies, and promote the democratization and scientization of public administration in China.

Keywords: Social organization, Public policy process, Institutionalized participation Fawkes and Miller's monographs "Post Modern Public Administration - discourse point", which put forward a developing dialogue mode to stimulate public participation consciousness in order to ensure the effective implementation of public administration based on the reflection of modern and post-modern public administration in the United States, and based on the construction of discourse theory, This theory has a good reference for us to push forward the reform of government governance and realize the benign interaction between the
\end{abstract}


government and society.

\section{Discourse Theory: The Theoretical Basis of Government's Public Policy Reform}

\subsection{Criticism of the Traditional Public Administration Paradigm}

Fawkes and Miller believe that the traditional mode of governance has disappeared and been replaced by new institutionalism or constitutionalism, communitarianism or citizenship. However, Fawkes and Miller both criticized the two alternative models. First, it is pointed out that "the reason that constitutionalism is not suitable for us is that it is too conservative", and that the declaration of the new institutionalism "the black Fort declaration" has the danger of attaching to the system, and points out that Giddens' structural theory can provide help, "beyond the system, and by placing social structure in a certain society to explore the influence of the system in the relationship." Second, they judge that although communitarianism is "replacing ring democracy with direct contact with managers and democracy", "communitarianism cannot tolerate the indifference of future citizens." We just think there is a reason for civic indifference. Finally, Fawkes and Miller put forward the third substitutes of the discourse theory as the traditional administrative model because the purpose of the discourse theory is to prove that "in the post modern mass consumer society, the best democracy we can get is a kind of non apathetic discourse, the condition of which the public enters the discourse is political intention".

\subsection{The Dilemma and Breakthrough of Postmodern Public Administration: Discourse Theory}

According to Fawkes and Miller, the foundation of discourse theory mainly includes four conceptual systems: phenomenology, constructivism, structural theory and public energy field. The concept of "public energy field" has the most practical significance for the theory and practice of public service in modern society. With regard to the connotation of the energy field, Fawkes and Miller stressed that "the energy field does not open up a feasible interpretation channel for top-down bureaucratic orders and the control of policy implementation". The public energy field can be actively or negatively controlled by various types of participants and participatory modes. "The public energy field, where is a performing society discourse, where is public policy formulated and revised." Fawkes and Miller categorized the form of discourse in the public energy field: the dialogue of the minority (the bureaucratic monologue manipulation dialogue), the dialogue of the majority (the postmodern anarchist expressionist discourse) and the dialogues of some people in the policy network (real public discourse). They also emphasizes that the discourse network of public interest provides a feasible model for public administration beyond the hierarchy in the post-modern situation.

In this policy network discourse structure, "some policy networks, inter institutional associations and community special groups show the potential of discourse", and find that there are think-tank experts, legislators, policy analysts, public administrators, interested citizens, procedural generalists, and even elected officials, sometimes meaningful, contextual real discourses emerge in this pattern.

\section{2. "Synergy Interaction" - The Mode of Participation and Influence of Public Policy by Social Organizations}

The so-called public policy refers to policies formulated by the government to solve social 
and public affairs and achieve social and public interests. "Social organization" is a more commonly used concept in China. The social organization referred to in this article refers to the three types of organizations, such as social organizations, private non enterprise units and foundations, which are included by civil affairs departments at all levels as registration management organs, and included in the scope of registration management. In foreign countries, organizations outside the government and outside the market are generally called "third sectors" or "non-profit organizations". After years of development, non-profit organizations have not simply been service providers, but they also represent the interests of special groups (such as children and the elderly), as well as the common needs of the public, such as environmental protection. Through policy advocacy, non-profit organizations require the government to take full account of the interests of the citizens in the formulation of public policies. On the one hand, it contributes to the realization of social fairness and justice, on the other hand, helps the formation of civil society.

The public policy participation of social organizations refers to non-governmental organizations using various channels to the government to convey the interests and requirements of the public, or to put forward various policy opinions and suggestions to help the government to improve public policy so as to ensure that the policy formulation meets the maximum interests of the people and ensures that the implementation of the policy does not deviate from the scheduled track. N G O is a concept contrasting to the government. Lester-M·Salamon defines NGO which has organization, folk, non-profit, autonomy, voluntary, non political and non religious attributes. This is a more authoritative definition. In China, there are two types of social organizations that meet the above seven attributes: social organizations and private non enterprise units. The Chinese NGOs mentioned in this article mainly refer to legally registered social organizations and private non-enterprise entities in China. Public policy process is a series of dynamic processes that identify policy issues, propose policy options, policy formulation, policy implementation, policy evaluation and policy termination. In a diversified society, the non-governmental organizations representing the will of citizens are becoming more and more important to the participation of the policy process. The government must adopt corresponding strategies and measures to expand the participation of non-governmental organizations in the process of public policy in order to promote the democratization and scientization of the public administration of our country.

The participation and influence of social organizations on public policy is a new form of cooperation between social organizations and government in the context of building a harmonious society. Soliciting community opinions in the process of formulating policies has become a part of the work of governments at all levels in developed countries and has become a common practice. The government provides funding to social organizations, and through continuous soliciting opinions from social organizations, it strengthens the participatory links between the government and the community.

The purpose of social organizations to participate in and influence public policy is to urge some of the government's policies into different interests: it may be for the interests of the members, such as a policy lobbying for the interests of the members of the industry association, or for some public interest, such as the environmental impact assessment of the environmental organization in the construction of the project. Estimate. Charity organizations 
offer policy recommendations to the government departments for social assistance and social services for the interests of vulnerable groups.

\section{The Way of Social Organizations Participate in and Influence Public Policy}

\subsection{Social Organizations Provide Policy Advice and Policy Recommendations}

Social organizations provide policy advice and policy recommendations through various channels to influence public policy. Social organizations investigate a certain question, provide reports, and put forward countermeasures and suggestions to the government voluntarily or at the request of the public. For example, the department of social work service in Shushan district Hefei is a professional civil service organization which will carry out a demand survey of community special elderly service under the guidance and assistance of relevant government departments. The questionnaire has been completed. In the near future, the community volunteers are being recruited from Hefei communities and trained to participate in the investigation. The results of the survey will be analyzed by the service agency, so as to provide data support for Hefei to formulate relevant social policies.

\subsection{Social Organizations Participate in Formulating Public Policy}

When the government is making relevant policies, it will actively invite social organizations to participate and provide advice. It may also be that the social organizations have learned that the government is making relevant policies, offering suggestions, and thus affecting the formulation of public policies. For example, after three years of community special group (community children, the elderly) service, sevice unit of human social work in Hefei Baohe district and service unit of People's livelihood social work in Hefei Shushan District advice the Hefei municipal Bureau to Provide a venue for children and the elderly in the community and offer specific services on the basis of mastering a large number of community children, the elderly community service. The proposal was adopted by the Hefei Municipal Bureau of civil affairs, which promulgates the "construction and implementation plan" of "old and young active homes" in Hefei community, and the project was proposed to be completed for two years. The "old and young home" in each community has the functions of extracurricular tutoring and education, entertainment, knowledge lectures and training, providing learning activities for the community children, the elderly, the unemployed, reemployed, other residents and families to meet the needs of the people's cultural life and learning. The people's livelihood social work service will also continue to carry out service for community elderly, community youth and children on the platform of some "community old and young home" platform.

At present, the way and capability of dialogue between social organizations and the government are relatively limited, and the way for social organizations to participate in the formulation of public policies needs to be further expanded. From the perspective of development trends and prospects, it is inevitable for social organizations to participate in the formulation of public policies and continue to participate in the specific providers of government public services. Social organizations will gradually become the participants in Fawkes and Miller's discourse theory. 
3.3 Promoting Institutionalized Self-Discipline Mechanism and Strengthening Social Supervision Over Social Organizations

To improve the supervision system for non-governmental organizations, we must first promote the construction of institutionalized self-discipline mechanism. At present, there are many defects in moral driven self-discipline, that is, self-discipline is only a conscious action of a few moral virtuous people. Institutionalized self-discipline formed on the basis of multiple constraints and in the long-term interaction between actors and external environment. Institutionalized self-discipline does not exclude the role of morality in shaping people's behavior, but emphasizes the systematic constraints of formal and informal institutions, emphasizing the inner moral, external supervision and competitive environment. To realize the transformation from moral driven self-discipline to institutionalized self-discipline, we must strengthen and improve the legal policy framework, supervision system and external environment.

In addition to non-governmental organizations' self-discipline and government supervision, strengthening the supervision of non-governmental organizations also depends on social supervision. The social supervision of non-governmental organizations mainly includes the supervision of the public, the supervision of the news media and the supervision of social organizations. Therefore, we should strengthen the awareness of public supervision, strengthen the supervision of public opinion, and establish relevant supervision and evaluation organizations to create a social environment conducive to the development of non-governmental organizations and promote the role of non-governmental organizations to play the role of the policy.

\section{Summary}

In short, social organizations have become an important force in modern pluralistic society. In addition to giving full play to the leading role of the government, we should also pay more attention to and play the role of social organizations in the process of public policy. The social organization should cooperate with the government in order to resolve the contradictions in the process of public policy, promote social integration and promote social stability.

\section{Acknowledgement}

The work described in this paper was fully supported by 2017 research project "social science popularization digital communication mechanism and innovative development path research" (Project No.2017CX013), the research project of social science innovation and development in Anhui Province

\section{References}

Charles, J. J., Hugh, \& Miller, T. (2002). Post modern public administration -- Discourse on. Beijing: Renmin University of China press.

Chen, Q. Y., Yin, Y. F., \& Zeng, J. R. (2005). On public interest in public administration. Chinese administration, 2005(7).

Liao, H., Shi, G. L., \& Zhu, X. H. (2011). Management innovation and Enlightenment of foreign non-profit organizations. Beijing: China real press.

Wang, M. (2001). China's non-governmental public sector (I). Chinese administration, 
2001(5).

Yu, K. P. (2003). Incremental democracy and good governance. Beijing: Social Sciences Press.

Zheng, J. H. (2004). Policy participation and influence patterns of non-governmental organizations. China Administration, 2004(5).

Zhou, Z. R, \& Chen, Q. Y. (2002). Moral driven self-discipline and institutionalized self-discipline -- Research on the public responsibility and supervision mechanism of engineering. China's public administration in exploration. Guangzhou: Zhongshan University press.

\section{Copyright Disclaimer}

Copyright for this article is retained by the author(s), with first publication rights granted to the journal.

This is an open-access article distributed under the terms and conditions of the Creative Commons Attribution license (http://creativecommons.org/licenses/by/3.0/). 